\title{
RECENT DEVELOPMENT IN CLT CONNECTIONS PART I: IN-PLANE SHEAR CONNECTION FOR CLT BRACING ELEMENTS UNDER STATIC LOADS ${ }^{1}$
}

\author{
Tobias Schmidt \\ Research Scientist \\ E-mail: tobias.schmidt2@kit.edu \\ Hans Joachim Blaß* \\ Head of Department \\ Karlsruhe Institute of Technology \\ Research Centre for Steel, Timber and Masonry \\ Timber Structures and Building Constructions \\ Karlsruhe, Germany \\ E-mail: hans.blass@kit.edu
}

(Received August 2017)

\begin{abstract}
Cross-laminated timber (CLT) is already being used successfully in residential, commercial, and industrial buildings. The use of computerized numerical control (CNC) automatic processing machines and high degree of prefabrication in combination with relatively large elements lead to short erection time on building site and to potentially cost-effective constructions. High in-plane shear strength and stiffness of the CLT itself make CLT members especially suited for bracing elements with in-plane loads. However, some available connection techniques show limited load-carrying capacities and stiffness values in comparison with the shear capacity of CLT. To better use the potential of CLT under in-plane loading, so called contact joints were developed with increased stiffness and load-carrying capacities using CNC automatic processing machines.
\end{abstract}

Keywords: CLT, contact joints, in-plane shear connection, wall and floor diaphragms, bracing elements.

\section{INTRODUCTION}

Plates or diaphragms made of cross-laminated timber (CLT) are ideal members to transfer vertical and horizontal loads in buildings. The excellent mechanical properties of CLT combined with a high degree of prefabrication enable CLT members to be used in residential and other buildings, where steel and concrete are still the predominant building materials. Examples are industrial and commercial buildings, engineered timber structures in general, and medium- and high-rise inner-city buildings. However, the technical limit is far beyond 10 storeys. A recent example is the 18-storey Brock Commons

\footnotetext{
* Corresponding author

${ }^{1}$ This paper presents the results of an experimental investigation, a design proposal and spacing rules of shear connectors made of Beech LVL.
}

Student Residence at the University of British Columbia in Vancouver, Canada. Here, a hybrid system is used with a first storey made of structural concrete and 17 storeys of mass timber construction with glulam columns and CLT floors. The vertical loads of the 53-m high building are transferred by the timber structure, whereas horizontal loads are transmitted by the CLT floor diaphragms to the two concrete cores. Because the building footprint is $15 \mathrm{~m} \times 56 \mathrm{~m}$, the floor diaphragms require a large number of joints between single panels. The accumulated length of these edge joints in the 17 floor diaphragms is about $5 \mathrm{~km}$.

Earthquake or wind loads on buildings cause diaphragm action in CLT members. Because of their high shear strength and stiffness, CLT members are especially suited for these in-plane loads. However, fabrication, transport, and erection limit the potential size of CLT members. 
Consequently, wall or floor diaphragms are often composed of several smaller CLT elements joined at the edges (Fig 1). Using traditional connection techniques, eg nails, screws, or special CLT connectors (Kögl and Maderebner 2013), the edge connection only achieves between $10 \%$ and $30 \%$ of the shear capacity of the CLT itself. Of course, there are high-performance connection systems available (Polastri et al 2016), but they are expensive.

The shear strength and stiffness of a CLT member composed of several elements are governed by the load-deformation behavior of the edge connections. The load-carrying capacity of the CLT member and the shear connection, respectively, are hence not balanced and the high shear capacity of the CLT member cannot be exploited. To close the gap between the shear capacities of CLT and the shear connections, contact joints were developed. CNC automatic processing machines are already used to produce highcapacity contact connections for linear timber members (Enders-Comberg et al 2015). Stecher et al (2014) showed the use of dovetail connectors fabricated from Beech plywood to transfer shear along the edges of CLT members. In a first theoretical and experimental approach, more than 30 newly developed shear connections were considered (Schmidt and Blass 2016).

As a result of this first study, two different joints with different mechanical properties were chosen for a continued and in-depth experimental and numerical study. Whereas the first type of joint using Beech laminated veneer lumber (LVL) shear keys is very suitable for floor diaphragms of buildings in earthquake-prone regions, where high stiffness and load-carrying capacity but no energy dissipation is required, the second type including the steel plate fasteners is able to provide the necessary energy dissipation in CLT shear walls. Both are aiming at easy fabrication using automatic processing machines and quick assembly at the construction site.

This article describes one type of joint with hardwood LVL shear keys. A following article will consider a highly dissipative CLT edge joint using steel plates as fasteners.

\section{CONTACT JOINTS FOR CLT WALL AND FLOOR DIAPHRAGMS}

Figure 2 exemplarily shows the load-displacement curves of three different contact joints. The first connector oriented parallel to the joint line shows high initial stiffness and high load-carrying capacity. After a brittle shear failure, the connector shows a limited remaining load-carrying capacity, which mainly relies on the cross layers' shear strength. The stiffness and load-carrying capacity of the second-X-shaped-connector are significantly lower than the corresponding values of the first connector. However, the X-shaped connector advantageously is able to transfer loads parallel and
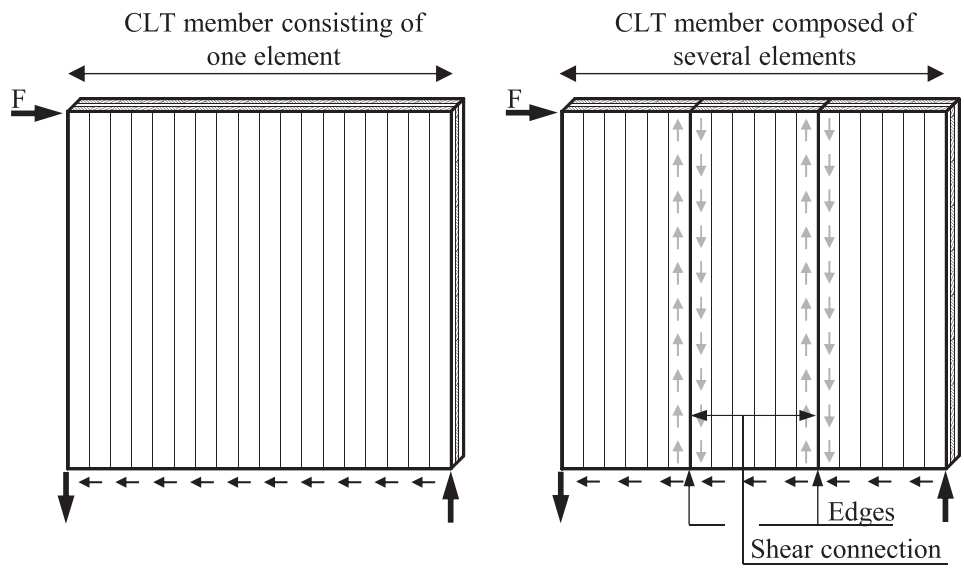

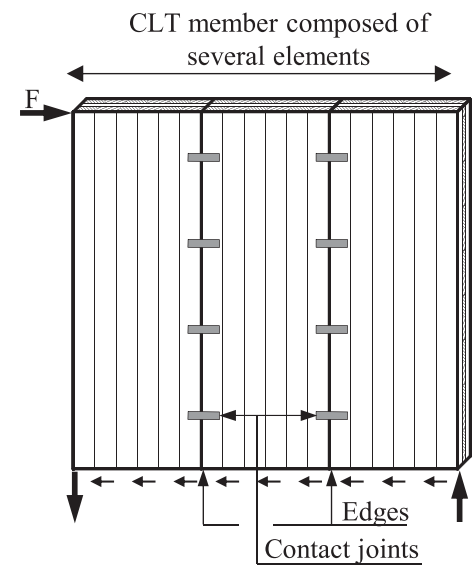

Figure 1. Cross-laminated timber (CLT) shear walls. 


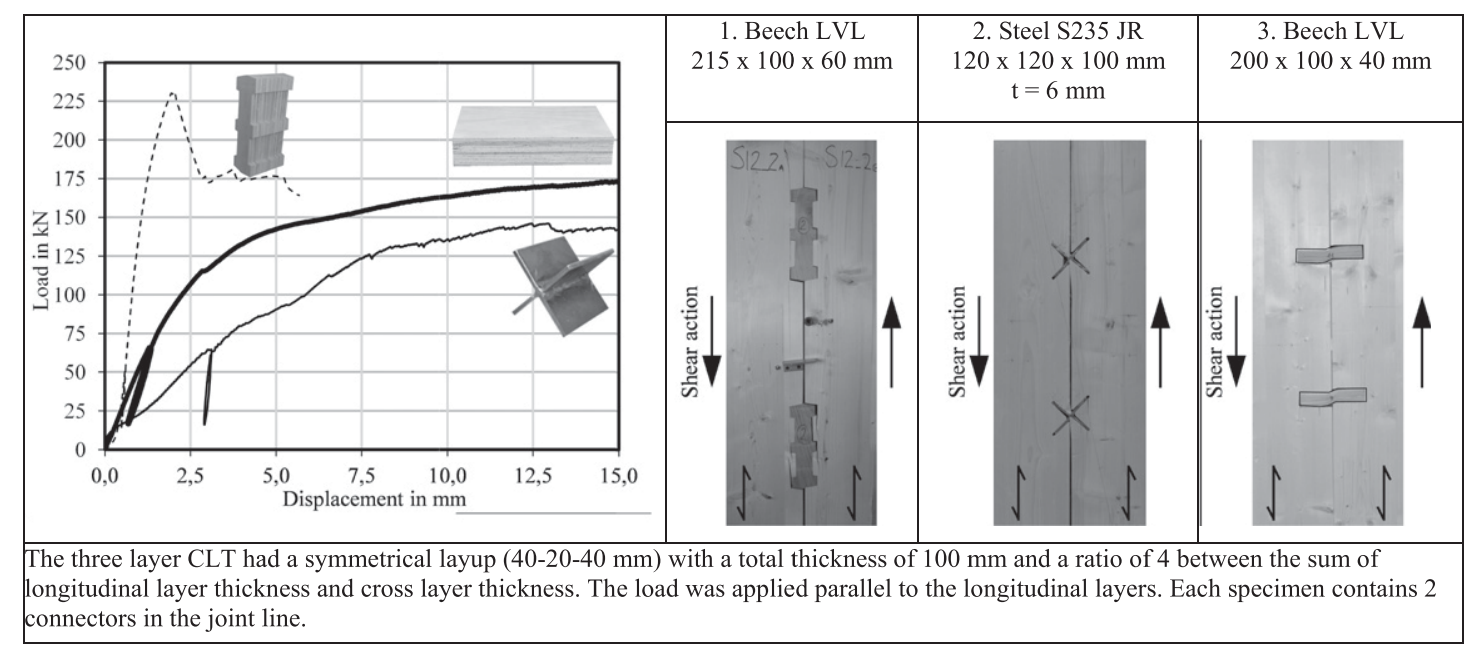

Figure 2. Load-displacement curves of different contact joints.

perpendicular to the joint line. The loaddisplacement behavior of the third connector oriented perpendicular to the joint line is in between the first two connector types. Both connectors 2 and 3 reach an ultimate joint displacement of $15 \mathrm{~mm}$ without a significant load decrease. In general, the load-displacement behavior is mainly influenced by the CLT layup as well as the connectors' material, geometry, spacing, and manufacturing precision.

Apart from requirements such as load-carrying capacity, stiffness or cost-effectiveness for connections in buildings, the robustness needs to be considered as well (Starossek 2005). Progressive failure should be excluded as far as possible. Connections may contribute to load redistribution in structures and hence to increased robustness, if they behave in a ductile manner. Figure 2 shows that a shear key made of Beech LVL loaded perpendicular to the grain seems to be a suitable compromise between load-carrying capacity, stiffness, and ductile behavior resulting in robust CLT wall or floor diaphragms (Schmidt and Blass 2016). Consequently, an in-depth investigation of LVL shear keys loaded perpendicular to grain is presented in the following paragraph.
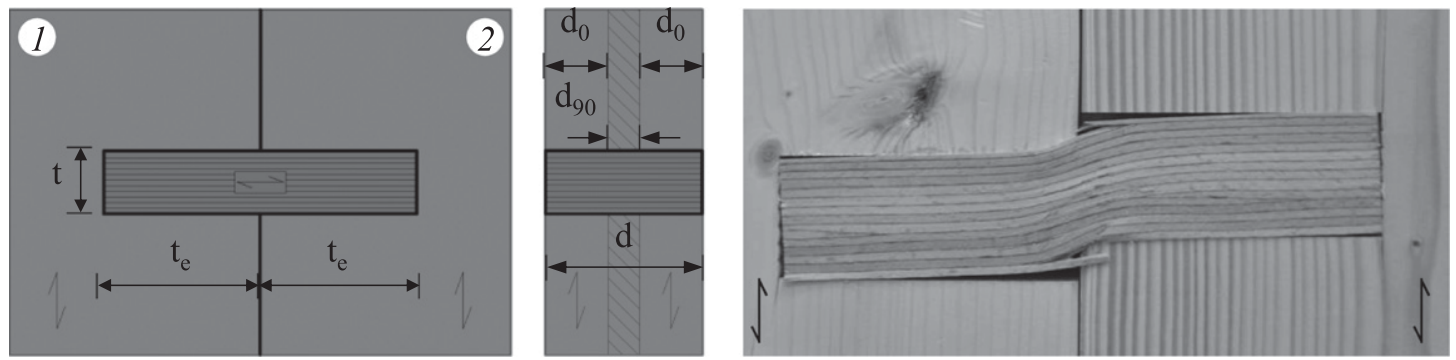

t

$t_{e} \quad$ Penetration length

d CLT thickness (100 mm)

$\mathrm{d}_{0} \quad$ Longitudinal layer thickness $(40 \mathrm{~mm})$

$\mathrm{d}_{90} \quad$ Cross layer thickness $(20 \mathrm{~mm})$

Figure 3. Shear key made of Beech LVL. 
Figure 3 shows the principal type of a contact joint for wall or floor diaphragms under static loads. The LVL shear keys are predominantly loaded in shear and compression perpendicular to the grain and show ductile load-deformation behavior. Mainly, the CLT members are loaded in compression parallel and perpendicular to the grain and in shear. The influence of shear key thickness $t$, penetration length $t_{\mathrm{e}}$, and the slenderness ratio $t_{\mathrm{e}} / t$ is studied here to further improve the load-carrying capacity and stiffness of the connection and to create a basis for an analytical model and a design proposal.

\section{MATERIALS AND METHODS}

The specimens including the CLT edge connection are symmetrical, ie the penetration length $t_{\mathrm{e}}$ is identical in both CLT members. Each specimen contained one shear key arranged in the edge of the CLT parts in the center of the joint line. The tests were performed according to the European Standard EN 26891 as compression shear tests (Fig 4). The slip parallel to the joint line was measured on both sides of the specimen using transducers. The evaluation of the test results is based on the load F parallel to the joint line and the average of both t readings.

European softwood (Norway spruce) CLT according to European Technical Approval ETA-11/0210 was used for the specimens. The three-layer CLT had a symmetrical layup (40-20-40 mm) with a total thickness of $100 \mathrm{~mm}$ and a ratio of 4 between the sum of longitudinal and cross layer thickness. Because of aesthetic reasons, the edges between adjacent longitudinal layer boards were bonded. However, for the edge bonding, a nonstructural adhesive is used and hence the edge glue lines must not be used in the determination of the in-plane shear strength of the CLT. The cross layers are not edge-bonded. The effective characteristic in-plane shear strength of the CLT according to ETA 11/0210 is hence only $f_{\mathrm{v}, \mathrm{k}}=1.6 \mathrm{MPa}$ for the full cross section. The average gross density of the CLT specimens is $455 \mathrm{~kg} / \mathrm{m}^{3}$ with a coefficient of variation $(\mathrm{COV})$ of $4.2 \%$. The average $\mathrm{MC}$ of the longitudinal layers is $10.7 \%$ (COV 10.0\%). The shear keys were produced from Beech LVL with an average density of $800 \mathrm{~kg} / \mathrm{m}^{3}$ (COV 2.0\%) and an MC of about 7.5\%. Twelve test

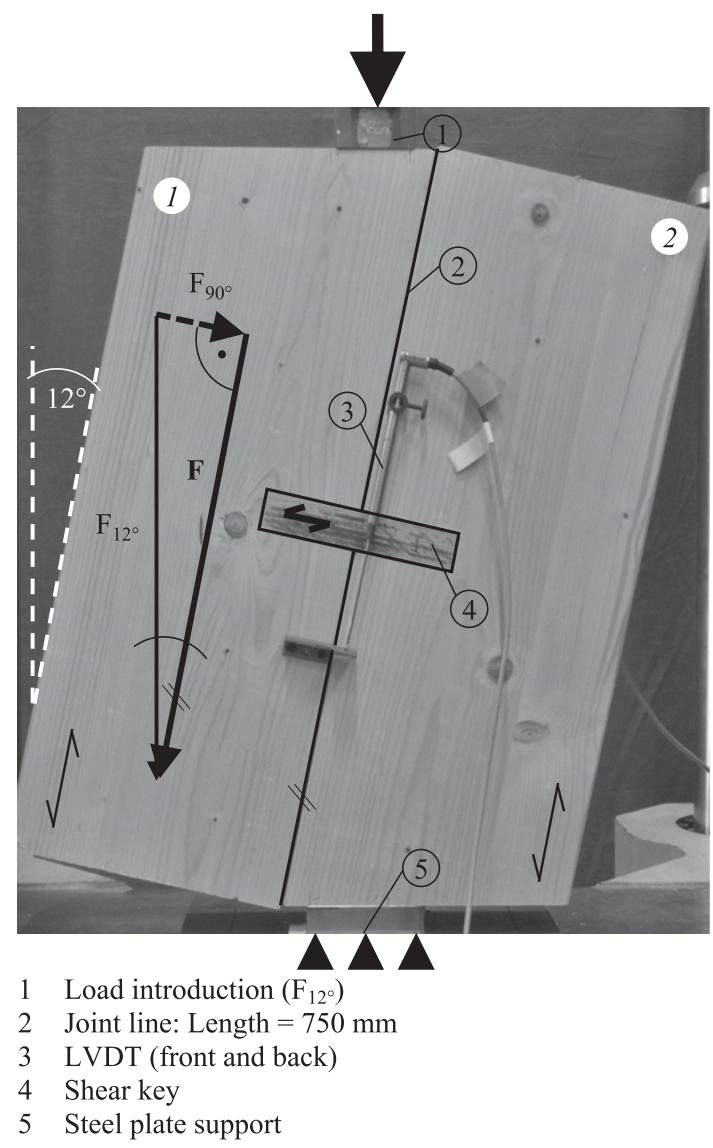

Figure 4. Test setup for compression shear tests.

series with five specimens each were performed using 25- or 40-mm-thick shear keys with slenderness ratios between 1 and 3.5 (Table 1). The bending strength of some Beech LVL shear keys was determined at random for both thicknesses. For the 25mm-thick shear keys, a mean bending strength of 129 $\mathrm{MPa}$ with a COV of $10 \%$ was determined; the corresponding values for the 40-mm-thick shear keys is $117 \mathrm{MPa}$ for the bending strength and a COV of $12 \%$.

\section{RESULTS AND DISCUSSION}

Ductile load-deformation behavior was observed for all test series independent of the slenderness ratio $t_{\mathrm{e}} / t$. Figure 5 shows connections with different slenderness ratios after reaching the ultimate deformation of $15 \mathrm{~mm}$. For lower slenderness ratios, the shear keys rotated during 
Table 1. Test program.

\begin{tabular}{lllllll}
\hline & $t=40 \mathrm{~mm}$ & & & \multicolumn{3}{c}{$t=25 \mathrm{~mm}$} \\
\cline { 1 - 2 } \cline { 5 - 6 } Series & $\lambda$ & $t_{\mathrm{e}}(\mathrm{mm})$ & & Series & \multicolumn{1}{c}{$\lambda$} & $t_{\mathrm{e}}(\mathrm{Mm})$ \\
\hline $40-1$ & 1 & 40 & & $25-1$ & 1 & 25 \\
$40-2$ & 1.5 & 60 & & $25-2$ & 1.5 & 37.5 \\
$40-3$ & 2 & 80 & & $25-3$ & 2 & 50 \\
$40-4$ & 2.5 & 100 & & $25-4$ & 2.5 & 62.5 \\
$40-5$ & 3 & 120 & & $25-5$ & 3 & 75 \\
$40-6$ & 3.5 & 140 & & $25-6$ & 3.5 & 87.5 \\
\hline
\end{tabular}

the test, whereas for slenderness ratios exceeding $\lambda=2.0$, the shear keys were clamped in the CLT members. All specimens showed compression perpendicular to grain deformation in the shear keys, compression parallel to grain deformation in the CLT members and local splitting in the longitudinal layers of the CLT members at the end of the shear keys (Fig 5). The load-carrying capacity $F_{\max }$ was defined as the maximum load before a relative displacement parallel to the joint line of $15 \mathrm{~mm}$ was achieved. For slenderness ratios $<2.0$, the load-carrying capacity depends on the embedded length (Fig 6). Figure 7 shows the load-displacement diagrams for the $40-\mathrm{mm}$ thick shear keys. A relative displacement of $15 \mathrm{~mm}$ was reached for all specimens with shear key thickness $40 \mathrm{~mm}$ without significant load decrease. The corresponding displacement for 25 -mm-thick shear keys was about $12 \mathrm{~mm}$. For slenderness ratios above 2 , the ultimate load remains at the same level. Table 2 summarizes the test results. The COV of the ultimate load is between $2.1 \%$ and $8.5 \%$ for shear key thickness $40 \mathrm{~mm}$ and between $4.9 \%$ and $13.2 \%$ for shear key thickness $25 \mathrm{~mm}$. The COV of the slip modulus is between $4.0 \%$ and $9.5 \%$ for shear key thickness $40 \mathrm{~mm}$ and between $9.6 \%$ and $43.8 \%$ for shear key thickness $25 \mathrm{~mm}$.
For larger connector slenderness ratios $\lambda \geq 2.0$, the load-deformation behavior is significantly influenced by the compression perpendicular to grain failure of the shear key close to the joint line. The influence of other parameters decreases because the slender shear key is clamped into the indentation in the CLT member. This prevents rotation of the shear key and limits plastic compression deformation to a small area close to the joint line, whereas connectors with a low slenderness ratio also cause plastic compression deformation at the connector ends both in the CLT parallel to the grain and in the connector perpendicular to the grain. Figure 8 (left) shows the distribution of compression stresses perpendicular to the grain in a 40-mm-thick shear key at a joint displacement of $15 \mathrm{~mm}$. The uneven stress distribution over the width of the connector caused by the different stiffness of the CLT longitudinal and cross layers is obvious. Plastic compression deformations only occur close to the joint line; at the shear key ends, the stresses remain in the elastic range. The uneven distribution of plastic compression deformation over the shear key width can also be observed in Fig 8 (right). Apart from compression failure perpendicular to grain in the CLT longitudinal layer contact areas, the shear key also shows bending and shear failure when loaded up to $15 \mathrm{~mm}$ joint displacement. If the joint deformation is limited to $12 \mathrm{~mm}$, the failure mode of slender shear keys predominantly is compression perpendicular to grain close to the joint line. The compression stresses further away from the joint line remain in the elastic range. A simplified design method hence should take into account this failure mode. In the load-displacement curves, a significant strengthening effect could not be observed and
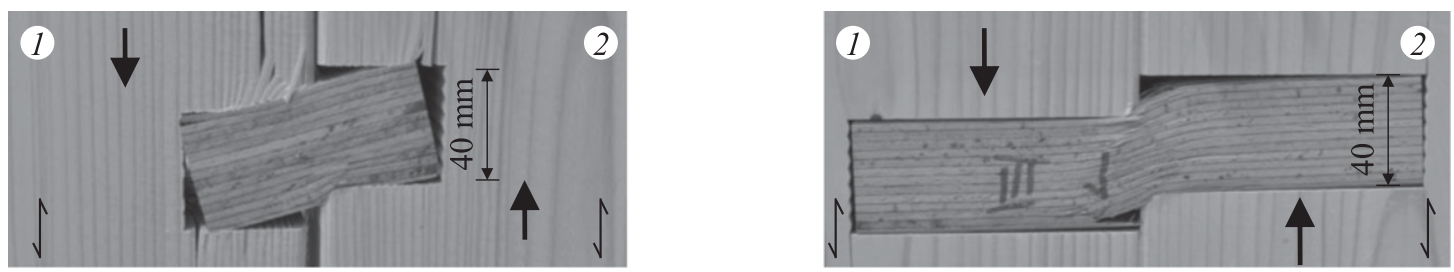

Figure 5. Connection with slenderness ratio $\lambda=1$ (left) and $\lambda=2.5$ (right) after the test. 


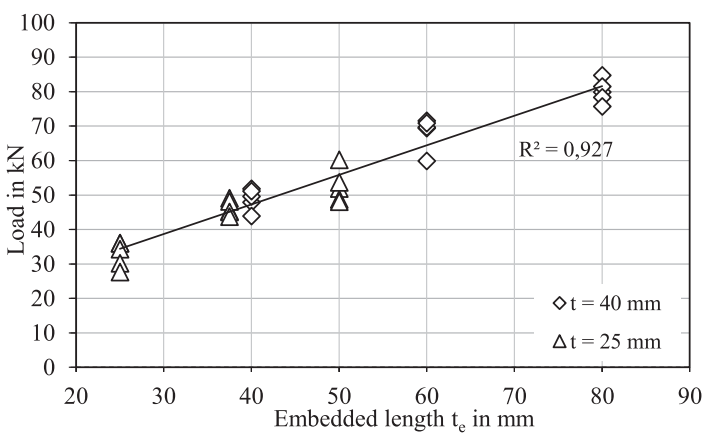

Figure 6. Correlation between the embedded length and the load-carrying capacity $(\lambda \leq 2.0)$.

consequently, a significant rope effect does not occur. A numerical study with varying friction coefficient values not shown here confirms this observation.

\section{Design Method}

Even though the real failure mode is a complex interaction of several failure modes, including bending, shear, and compression perpendicular to grain, the governing failure mode is compression perpendicular to grain of the Beech LVL. To derive a simple and robust design method, only compression perpendicular to grain of the Beech LVL is considered. This method is derived from a design method for reinforced concrete beams with a user-defined compression zone. In Germany, the same approach was used for timber columns directly clamped in concrete foundations
(Heimeshoff and Eglinger 1981). Figure 9 (left) shows the assumed stress distribution perpendicular to the Beech LVL shear key. After formulating moment and force equilibrium, transformations and simplifications lead to the design $\mathrm{Eq} 1$.

$$
F_{\mathrm{v}, \mathrm{Rk}}=\left\{\begin{array}{c}
\sum_{i} d_{0, \mathrm{i}} \cdot 0.8 \cdot f_{\mathrm{c}, 90, \mathrm{EN} 408, \mathrm{k}} \cdot k_{\mathrm{con}} \cdot \frac{t_{\mathrm{e}}}{2} \\
\text { for } 1.0 \leq \lambda \leq 2.0 \\
\sum_{i} d_{0, \mathrm{i}} \cdot 0.8 \cdot f_{\mathrm{c}, 90, \mathrm{EN} 408, \mathrm{k}} \cdot k_{\mathrm{con}} \cdot t \\
\text { for } \lambda>2.0
\end{array}\right.
$$

Here, $25 \mathrm{~mm} \leq t \leq 40 \mathrm{~mm} ; t_{\mathrm{e}, 1}=t_{\mathrm{e}, 2}$; center-tocenter spacing between two consecutive shear keys and loaded end parallel to the joint line $\geq 11 t ; t$ : shear key thickness; $f_{\mathrm{c}, 90, \mathrm{EN} 408, \mathrm{k}}$ : compression strength of the LVL shear key perpendicular to grain, determined according to EN 408; $k_{\text {con: }}$ modification factor $\left(k_{\text {con }}=2.75\right)$; $\Sigma d_{0, \mathrm{i}}$ : sum of longitudinal layer thicknesses; slenderness $\lambda=t_{\mathrm{e}} / t$.

Additional compression tests perpendicular to the grain of Beech LVL (unpublished) were carried out to determine strength values depending on the deformation. In this special case, these strength values are more realistic than EN 408-based values because the compression deformation in the additional tests complies with the deformation of the shear keys in the connection. This is in contrast to common tests, eg according to $\mathrm{EN}$

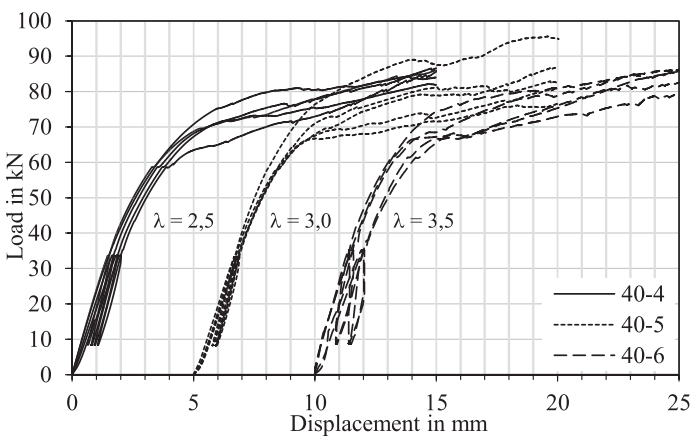

Figure 7. Load-displacement curves of connections with 40-mm-thick shear keys. To improve readability, load-slip curves are partly moved to right on the abscissa. 
Table 2. Test results.

\begin{tabular}{|c|c|c|c|c|c|c|c|}
\hline \multicolumn{4}{|c|}{$t=40 \mathrm{~mm}$} & \multicolumn{4}{|c|}{$t=25 \mathrm{~mm}$} \\
\hline Series & $\lambda$ & $F_{\text {max,mean }}(\mathrm{kN})$ & $k_{\mathrm{s}, \text { mean }}(\mathrm{kN} / \mathrm{mm})$ & Series & $\lambda$ & $F_{\text {max,mean }}(\mathrm{kN})$ & $k_{\mathrm{s}, \text { mean }}(\mathrm{kN} / \mathrm{mm})$ \\
\hline $40-1$ & 1 & 48.9 & 15.2 & $25-1$ & 1 & 32.9 & 16.9 \\
\hline $40-2$ & 1.5 & 68.3 & 18.0 & $25-2$ & 1.5 & 46.3 & 22.9 \\
\hline $40-3$ & 2 & 80.1 & 19.4 & $25-3$ & 2 & 52.5 & 18.5 \\
\hline $40-4$ & 2.5 & 84.9 & 20.5 & $25-4$ & 2.5 & 55.4 & 18.8 \\
\hline $40-5$ & 3 & 84.6 & 21.3 & $25-5$ & 3 & 58.7 & 23.2 \\
\hline $40-6$ & 3.5 & 84.0 & 20.9 & $25-6$ & 3.5 & 57.7 & 21.0 \\
\hline$k_{\mathrm{s}}$ & \multicolumn{3}{|c|}{ Slip modulus } & & & & \\
\hline
\end{tabular}

408, where the compression strength perpendicular to grain is determined at a significantly lower deformation.

The modification factor $k_{\mathrm{con}}$ is calibrated based on characteristic values and considers the following:

- higher strength values perpendicular to grain of the Beech LVL shear key than $f_{\mathrm{c}, 90, \mathrm{EN} 408, \mathrm{k}^{-}}$ values because of higher compressive deformation of the shear key;

- different compression stress distributions perpendicular to the grain of the shear key between the real situation in a connection and in the additional compression tests;

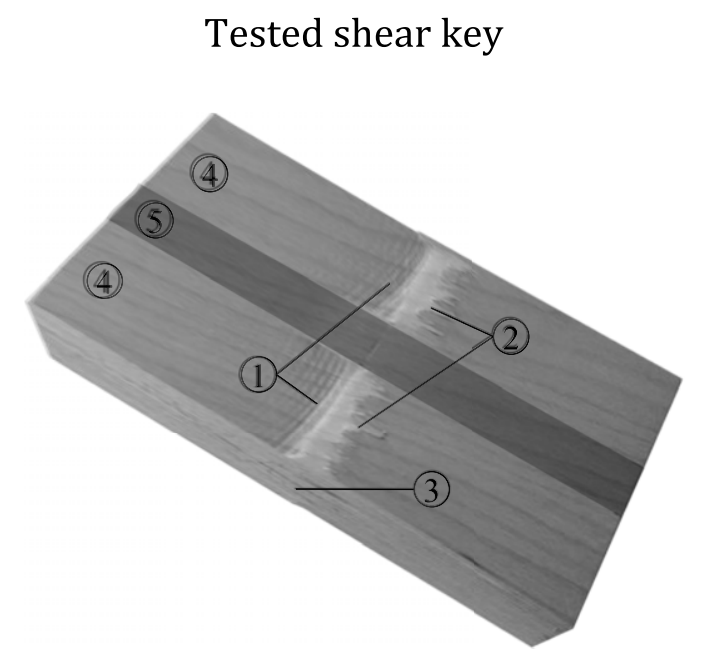

- contribution of protruding fibers of the shear key in the contact area of the CLT longitudinal layer and the shear key.

Figure 9 (right) shows the result of the calculated characteristic load-carrying capacity according to Eq 1 in comparison with the test results at $12-\mathrm{mm}$ displacement in the joint line. Twelve millimeter was chosen to limit the potential interstorey drift of the walls composed of several CLT elements. Because the contribution of the CLT cross layer to the load-carrying capacity is about $3 \%$, the design proposal only considers the contribution to the loadcarrying capacity of the CLT longitudinal layers. It

\section{Shear key: FE-model} (Mahler 2016)

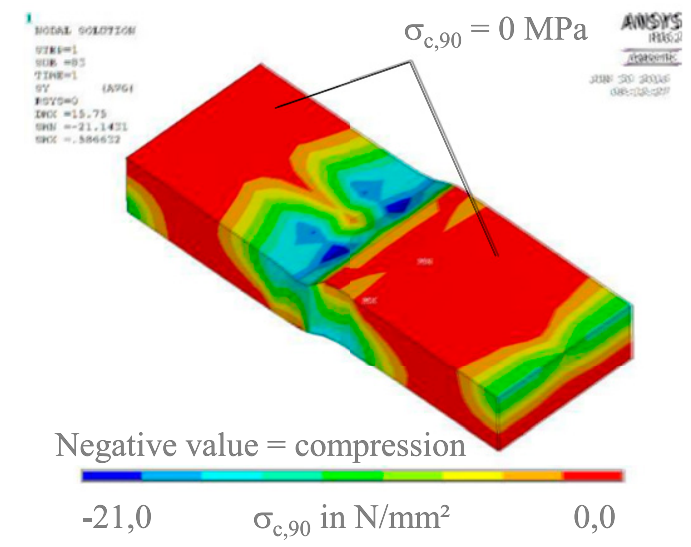

\begin{tabular}{llll}
\hline 1 & Plastic compression perpendicular to grain & 4 & CLT longitudinal layer contact area \\
2 & Bending failure in the outermost tensile fibres & 5 & CLT cross layer contact area \\
3 & Shear failure & $\sigma_{c, 90}$ & Stress perpendicular to grain \\
\hline
\end{tabular}

Figure 8. Shear key after the test (left) and distribution of compression stresses perpendicular to grain from finite element results (right). 

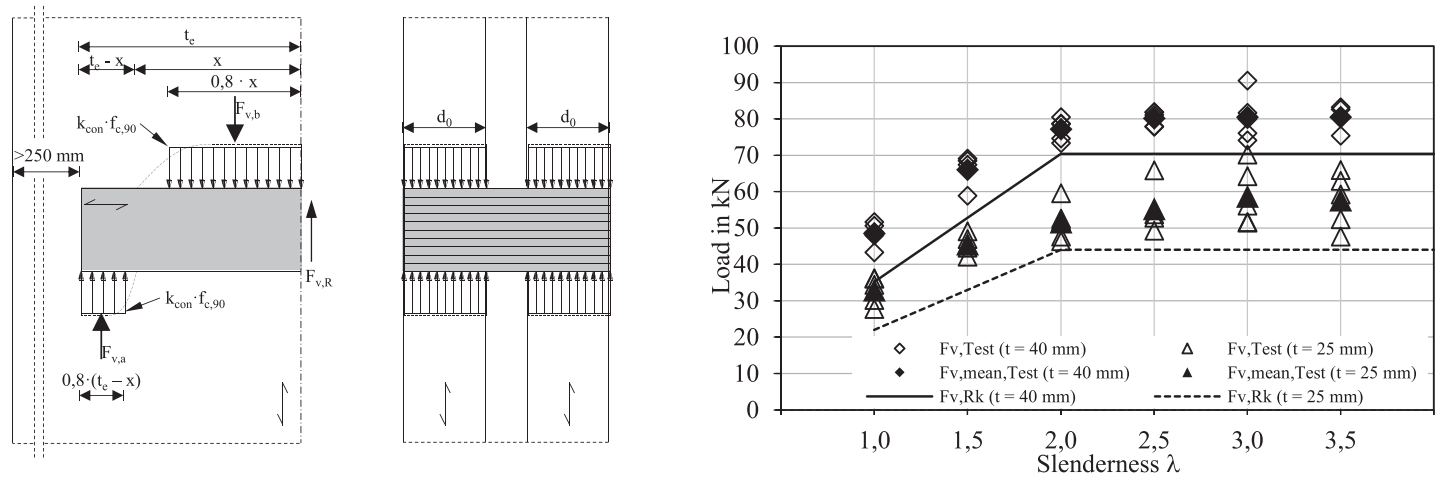

Figure 9. Mechanical model and assumed stresses for slenderness $\leq 2.0$ (left) and test results in comparison with the determined characteristic load-carrying capacity $F_{\mathrm{v}, \mathrm{Rk}}$ based on the design model (right).

seems that the simple mechanical model is a sufficiently correct approach for all considered slenderness ratios to calculate the load-carrying capacity of Beech LVL shear keys loaded perpendicular to grain.

For CLT layup used in the tests, a single Beech LVL shear key with 40-mm thickness and a slenderness ratio $\geq 2.0$ reaches a characteristic loadcarrying capacity of $F_{\mathrm{v}, \mathrm{Rk}}=70.4 \mathrm{kN}\left(f_{\mathrm{c}, 90, \mathrm{k}}=\right.$ $10 \mathrm{MPa})$. Because an in-plane shear connection in the edges of CLT members consists of several consecutive shear keys in a joint line, it is obvious that consideration of a single connector is not sufficient. A longitudinal shear failure of the CLT needs to be considered as well because this failure mode caused a significant load decrease in some load-displacement curves of the shear key connections.

\section{Spacing Rules and Effective Number of Connectors}

To determine minimum spacing in longitudinal direction, two test series with six tests using the same CLT material as described previously were carried out (shear key thickness $t=40 \mathrm{~mm}$, slenderness $\lambda=2.5$ ). The tests were performed according to EN 26891 as compression shear tests. As described previously, the specimens including the CLT edge connections are symmetrical. Each specimen contained two shear keys arranged in the edges of the joint line. Two additional recesses at the beginning and the end of the joint line without a shear key make sure that the CLT shear stresses were similar to the situation in a continuous joint line. The difference between the two test series is the spacing between the shear keys.

A small shear key spacing (7.25t) finally leads to longitudinal CLT shear failure (Fig 10, left). After brittle shear failure, the connection showed a reduced load-carrying capacity. This failure mode can largely be avoided with an increasing spacing of $11 t$. Then mostly a displacement of $15 \mathrm{~mm}$ was reached without significant load decrease, whereas the most prominent failure mechanism is perpendicular to grain compressive failure of the shear key (Fig 10, right). Furthermore, a larger shear key spacing has a significant influence on the load-carrying capacity $+12.9 \%$ (Fig 10, middle). Connection stiffness was hardly influenced by shear key spacing.

The remaining load-carrying capacity after brittle shear failure of the CLT with small spacing may be explained by the following mechanism: because of the higher shear stiffness of the longitudinal layers before the first shear failure, the load is nearly completely transferred from the shear key into the end grain surfaces of the CLT longitudinal layers. After a sudden shear failure within the longitudinal layer, two possible load paths remain: part of the load is transferred from the longitudinal layers via rolling shear into the cross layer and another part into the contact area 


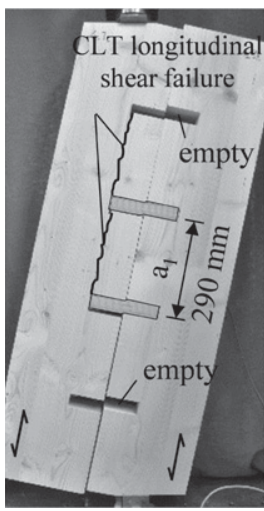

$\mathrm{F}_{\text {max,mean }}=143 \mathrm{kN}$ (COV $7.6 \%)$

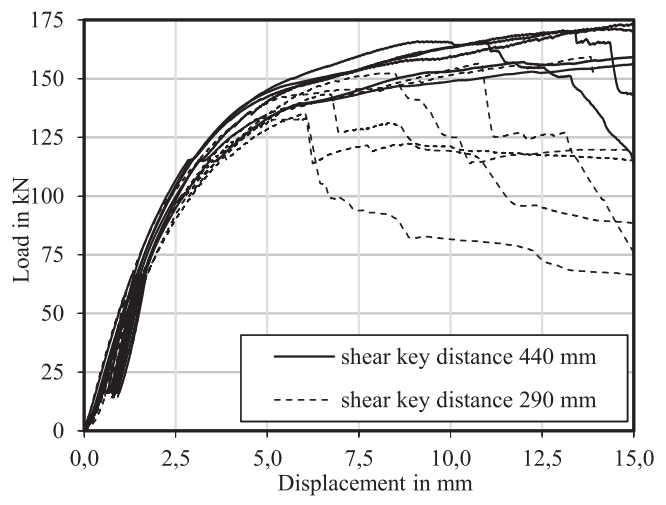

Figure 10. Compression shear test with different spacing.

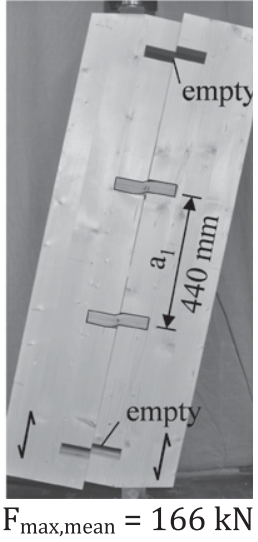

(COV $4.2 \%)$ of the cross layers perpendicular to the grain. The shear capacity of the cross layer hence explains the remaining shear capacity after first brittle failure.

As expected, the average load-carrying capacity of two consecutive shear keys does not reach the same level as two times the load-carrying capacity of a single shear key (test series 40_4: $2 \cdot F_{\max }=2 \cdot 85.2 \mathrm{kN}=170 \mathrm{kN}$ compared with $166 \mathrm{kN}$, see Fig 10, right). In this configuration with $11 \cdot \mathrm{t}$, the effective number is $n_{\mathrm{ef}}=1.94$. To verify the influence of the number of shear keys in a joint line on the load-carrying capacity, a numerical study will consider consecutive shear keys with different load-displacement curves and different production inaccuracies.

\section{CONCLUSIONS}

Shear keys made of Beech LVL and loaded perpendicular to the connector plane show ductile load-displacement behavior. A possible brittle shear failure of CLT between two consecutive shear keys is avoided by minimum spacing of 11 times the shear key thickness. If additionally a minimum slenderness ratio of 2.0 is observed, the connections achieve high load-carrying capacity with low variation. The higher the slenderness ratio, the lower the fastener rotations and the subsequent forcing apart of two connected CLT members. Secondary connections are necessary to transmit these forces perpendicular to the joint line.

The joints for floor diaphragms were also modeled numerically and a good agreement between test and simulation results was found. An analytical model was derived to determine the loadcarrying capacity. Because the load between CLT and shear key is transferred via the longitudinal layers of CLT, the load-carrying capacity primarily depends on the contact are between CLT longitudinal layers and Beech LVL connector. Consequently, the proposed design model only considers the accumulated longitudinal layer thicknesses and the compression strength perpendicular to grain of the Beech LVL shear key.

Further refining of the connection geometry as eg a tapered shape will lead to a quick assembly. Here, further numerical and experimental studies will follow.

Although the fastener is wood based, the joints show ductile load-slip behavior. Beech LVL or Beech plywood seems to be a very suitable material for these wood-based connectors.

Although shear keys made of Beech LVL are very suitable for floor diaphragms or shear walls of buildings where high stiffness and load-carryingcapacity but no energy dissipation are required, a recently developed steel plate fastener with gap is able to provide the necessary energy dissipation in 
CLT shear walls in earthquake-prone regions. A second publication covers the results of an experimental and analytical investigation related to dissipative CLT connections.

\section{REFERENCES}

Enders-Comberg M, Frese M, Blass HJ (2015) Beech LVL for trusses and reinforced glulam. Bautechnik 92, Heft 1, Pages 9-17. DOI: 10.1002/bate.201400076 (Article in German).

Heimeshoff B, Eglinger W (1981) Einspannung von Holzstützen durch Verguss im Betonfundament. Untersuchungsstufe I. Lehrstuhl für Holzbau und Baukonstruktionen, Technische Universität München. IRB Verlag, Stuttgart.

Kögl J, Maderebner R (2013) System connectors for crosslaminated timber panels. In 19. Internationales HolzbauForum, Garmisch-Partenkirchen.

Mahler P (2016) Experimentelle und numerische Untersuchung zur Tragfähigkeit von Kontaktverbindungen in
Brettsperrholz (in German). Master's thesis, July 2016, Karlsruhe Institute of Technology, Timber Engineering and Building Construction, Karlsruhe.

Polastri A, Giongo I, Pacchioli S, Piazza M (2016) Structural analysis of CLT multi-storey buildings assembled with the innovative X-RAD connections system: Case-study of a tall building. In Proc. 2016 World Conference on Timber Engineering (WCTE), August 22-25, World Conference on Timber Engineering, Vienna, Austria.

Schmidt T, Blass HJ (2016) Contact joints in engineered wood products. In Proc. 2016 World Conference on Timber Engineering (WCTE), August 22-25, World Conference on Timber Engineering, Vienna, Austria.

Starossek U (2005) Progressiver Kollaps von Bauwerken. Beton-und Stahlbetonbau, Sonderdruck, Heft 4, Pages 315.

Stecher G, Kögl J, Beikircher W (2014) Mechanical behavior of dove-tail connections for Cross Laminated Timber wall elements. In Proc. 2014 World Conference on Timber Engineering (WCTE), August 10-14, World Conference on Timber Engineering, Quebec City, Canada. 